\title{
NECROLOGÍA
}

\author{
M. ${ }^{a}$ Luisa Cabanes Catalá \\ Universidad de Alicante
}

En las kalendas de febrero, en la ciudad de Valencia moría a los 68 años de edad, Antonio Ubieto Arteta. La noticia de su fallecimiento causó sorpresa, ya que la discreción había presidido la grave enfermedad, conocida sólo por unos pocos.

Con su muerte se cierra una página importante del Medievalismo Español y, porqué no decirlo, con él ha desaparecido un estilo de medievalista, cuyas raíces se entroncaban con don Claudio Sánchez Albornoz, maestro de don José M. ${ }^{a}$ Lacarra, quien a su vez lo fue suyo.

Había nacido en Zaragoza el 31 de marzo de 1923, la profesión de su padre, jefe de estación, hizo que cursara el bachillerato en los institutos de Huesca, Zaragoza y Tudela y, sin duda, influyó también en su espíritu viajero.

En 1941 comienza en la Facultad de Filosofía y Letras de Zaragoza los estudios de licenciatura, que culminará con Premio Extraordinario. En 1949, defendió en la Universidad de Madrid su Tesis Doctoral, La colección diplomática de Pedro I, con la que obtuvo el Premio Extraordinario de Doctorado.

Su actividad en la Universidad se inició en 1945 en la Facultad de Filosofía y Letras de Zaragoza y hasta 1954 desempeñó los cargos de Ayudante de Clases Prácticas, Auxiliar Temporal y Profesor Adjunto Interino. El 30 de septiembre de 1954 ingresaba en el Cuerpo Facultativo de Archiveros, Bibliotecarios y Arqueólogos, con destino provisional en Zaragoza. Pasó en 1956 a León, donde se encargó de la Biblioteca Pública, Centro Coordinador de Bibliotecas, Biblioteca de la Facultad de Veterinaria y Archivo de la Delega- 
ción de Hacienda, hasta el 27 de noviembre de 1956 en que solicitó la excedencia voluntaria. Un año antes, el 16 de diciembre de 1955 había obtenido, por concurso-oposición, la cátedra de Prehistoria e Historia Antigua y Media de España e Historia General de España (Antigua y Media) de la Universidad de Santiago de Compostela; además, en diciembre de 1956, fue nombrado por el rector compostelano Comisario-Director de la Escuela de Artes y Oficios, desempeñando ambos cometidos hasta su incorporación a la Universidad de Valencia el 1 de febrero de 1958. Ya en Valencia solicitó, el 18 de agosto de 1958, el reingreso en el Cuerpo Facultativo, ocupándose del Archivo de la Delegación de Hacienda y del de la Audiencia de Valencia hasta la excedencia definitiva el 14 de agosto de 1959, quedando desde ese momento dedicado por completo al magisterio universitario.

En la Universidad de Valencia, permaneció casi veinte años como catedrático de Historia Antigua y Media de España y Director del Departamento de Historia Medieval. Asimismo fundó en 1968 la revista «Ligarzas» de la que fue su director. Su estancia coincide con uno de los momentos más brillantes de la Sección de Historia de la Facultad de Filosofía y Letras, puesto que concurrió su magisterio con los profesores Reglá, Jover, López Gómez, Tarradell, entre otros.

En su larga etapa en Valencia, fundó la editorial Anubar, con una clara orientación, la publicación de fuentes y trabajos de investigación. De entre sus colecciones merecen destacarse la de Textos Medievales, con cerca de un centenar de título, la serie de Comercio Valenciano, la de Obras de Investigación o la de Temas Valencianos, esta última con un carácter divulgativo, que vio nacer, cuando se trasladó a Zaragoza, su gemela aragonesa, Los A/corces.

La jubilación de su maestro el profesor Lacarra, hicieron que desease volver a su ciudad natal y suceder a su maestro en la Universidad Zaragozana, lo que se produjo en 1977. Desde esa fecha hasta su jubilación, el 31 de marzo de 1988, estuvo al frente de la Cátedra de Historia Medieval y del Departamento del mismo nombre. A fines de 1988 fue nombrado Emérito por la Universidad de Zaragoza, categoría que desempeñaba en el momento de su fallecimiento. Enemigo de los cargos, sólo tuvo a lo largo de su amplia vida académica y por breve período de tiempo, el de secretario de la Facultad de Filosofía y Letras de Valencia, en año de su incorporación, y el de Decano de la de Zaragoza, por breve tiempo.

De los más de 200 títulos que componen su producción bibliográfica, resulta difícil entresacar y resaltar alguno, de ahí que destaquemos sólo las lí- 
neas de investigación más relevantes entre las que debe mencionarse la edición de fuentes (colecciones diplomáticas, ediciones de crónicas), la temática navarro-aragonesa, la valenciana y la épica.

En su Aragón natal encontró el reconocimiento institucional, ya que en 1989, el día de San Jorge, recibió de la Diputación General el premio «Aragón» en el área de humanidades, como reconocimiento a su labor investigadora y, el pasado día del Pilar, el Ayuntamiento de Zaragoza le nombró Hijo Predilecto de la Ciudad.

Los que tuvimos la fortuna de tenerlo como maestro, no podremos olvidar jamás su rectitud, integridad, sencillez, talante humano, pero especialmente su magisterio y espíritu de viajero infatigable. 



\section{BIBLIOGRAFÍA (1)}

(1) «El fuero de Selgua», en Estudios de Edad Media de la Corona de Aragón, 1 (Zaragoza, 1945), p. 334-336.

(2) «Disputas sobre los obispados de Huesca y Lérida en el siglo XIls, en Estudios de Edad Media de la Corona de Aragón, 2 (Zaragoza, 1946), p. 187-240.

(3) «El Libro de San Voto», en Hispania Sacra, 3 (Madrid, 1950), p. 191-201.

(4) “La construcción de la colegiata de Alquézar (Notas documentales», en Pirineos 5 (Zaragoza, 1949), p. 253-266.

(5) «La participación navarro-aragonesa en la Primera Cruzada", en Príncipe de Viana, 8 (Pamplona, 1947), p. 357-383.

(6) «Homenaje de Aragón a Castilla por el condado de Navarra» en Estudios de Edad Media de la Corona de Aragón, 3 (Zaragoza, 1958), p. 7-28.

(7) Documentos particulares y eclesiásticos correspondientes al reinado de Pedro I de Aragón y Navarro, Zaragoza, 1945-1948 (inédita).

(8) "La introducción del rito romano en Aragón y Navarra» en Hispania Sacra, 1 (Madrid, 1948), p. 299-324.

(9) Colección diplomática de Pedro I de Aragón y de Navarra, Zaragoza, 1951.

(10) «Navarra-Aragón y la idea imperial de Alfonso VII de Castilla» en Estudios de Edad Media de la Corona de Aragón, 6 (Zaragoza, 1956), p. 41-82.

(11) "La fecha de la muerte de Ramiro II de Aragón», en Estudios de Edad Media de la Corona de Aragón, 3 (Zaragoza, 1947-48), p. 474-475.

(12) «Los relicarios de Loarre», en Estudios de Edad Media de la Corona de Aragón, 3 (Zaragoza, 1947-48), p. 476-480.

(13) «La "Campana de Huesca"» en Revista de Filologia Española, 35 (Madrid, 1951), p. 29-61.

(14) «Notas sobre la Crónica de San Juan de la Peña» en Pirineos, 6 (Zaragoza, 1950), p. 463-493.

(15) El Archivo municipal de Monzón, Zaragoza, 1949.

(16) «Monarcas navarros olvidados: los reyes de Viguera» en Hispania, 10 (Madrid, 1950), p. 3-24.

(17) «El origen ilerdense de la sede de Roda-Barbastro» en llerda número 20-21 (Lérida, 1957), p. 325-337.

(18) «La fecha de la construcción del claustro románico de la catedral de Pamplona» en Príncipe de Viana, 11 (Pamplona, 1950), p. 77-83.

(19) «El nacimiento de Alfonso Il de Aragón» en Estudios de Edad Media de la Corona de Aragón, 4 (Zaragoza, 1951), p. 419-425.

(20) "Mandatos navarros de Felipe III el Atrevido, rey de Francia" en Estudios de Edad Media de la Corona de Aragón, 4 (Zaragoza, 1951), p. 648-685.

(21) «El destierro del obispo compostelano Diego Gelmirez de Aragón» en Cuadernos de Estudios gallegos, 18 (Madrid, 1951), p. 43-51.

(22) «Qué año se celebró el concilio de Coyanza» en Archivos leoneses, 9 (León, 1951), p. 41-47. 
(23) «Doña Andregoto Galíndez, reina de Pamplona y condesa de Aragón» en Actas del Pri. mer Congreso Internacional de Estudios Pirenaicos, 6 (Zaragoza, 1952), p. 165-170.

(24) Catálogo del Libro Redondo de la Catedral de Pamplona, Zaragoza, 1951 (inédito).

(25) "La peregrinación de Alfonso II de Aragón a Santiago de Compostela» en Estudios de Edad Media de la Corona de Aragón, 5 (Zaragoza, 1952), p. 438-452.

(26) «Documentos para el estudio de la Numismática navarro-aragonesa medieval» en Publicaciones del Seminario de Arqueologia y Numismática Aragonesa, 1 (Zaragoza, 1951), p. 113-135.

(27) "Una narración de la batalla de Alcoroz atribuida al abad pinatense Aimerico» en Argensola, 2 (Huesca, 1951), p. 245-256.

(28) El Archivo municipal de Pintano, Zaragoza, 1952 (inédita).

(30) "La creación de la cofradía militar de Belchite" en Estudios de Edad Media de la Corona de Aragón, 5 (Zaragoza, 1952), p. 427-434.

(31) "Ayerbe: notas y sugerencias" en Argensola, 3 (Huesca, 1952), p. 1-10.

(32) «Un Pedro de Urdemalas del siglo Xl"» en Archivo de Filología Aragonesa, 5 (Zaragoza, 1953), p. 170-171.

(33) «Documentos para el estudio de la Numismática navarro-aragonesa medieval», en Publicaciones del Seminario de Arqueología y Numismática aragonesas, 2 (Zaragoza, 1953), p. 85-102.

(34) "La batalla de "Piedra-Pisada"” en Argensola, 3 (Huesca, 1951), p. 253-256.

(35) Cartulario de Montearagón (siglos XI-XII), Zaragoza, 1953 (inédita).

(36) «La reconquista y repoblación de Alcañiz» en Teruel, 9 (Teruel, 1953), 18 páginas.

(37) «Gonzalo, rey de Sobrarbe y Ribagorza» en Pirineos, 8 (Zaragoza, 1952), p. 299-325.

(38) "Observaciones al "Cantar de Mío Cid"" en Arbor n. ${ }^{\circ} 138$ (Madrid, 1957), 25 páginas.

(39) «El sitio de Huesca y la muerte de Sancho Ramírez» en Argensola, 4 (Huesca, 1953), p. 61 69 y $139-148$.

(40) «Episcopologio de Álava (siglos IX-X|) en Hispania Sacra, 6 (Madrid, 1953), p. 37-55.

(41) «Documentos para el estudio de la Numismática navarro-aragonesa medieval» en Caesaraugusta, 5 (Zaragoza, 1954), p. 147-159.

(42) «Antecedentes familiares de don Pedro Tuiz de Aragra, señor de Albarracín» en Teruel, 10 (Teruel, 1953), 12 páginas.

(43) «Ramiro I de Aragón y su concepto de la realeza» en Cuadernos de Historia de España, 20 (Buenos Aires, 1953), p. 45-662.

(44) «Las fronteras de Navarra» en Príncipe de Viana, 14 (Pamplona, 1953), p. 61-96.

(45) Crónica de los Estados Peninsulares. Texto aragonés del siglo XIV, Granada, 1955.

(46) "La diócesis navarro-aragonesas durante los siglos IX y X» en Pirineos, 10 (Zaragoza, 1954), p. 179-199.

(47) "Un mapa de la diócesis de Calahorra en 1257" en Revista de Arhivos, Bibliotecas y Museos, 60 (Madrid, 1954), p. 375-394.

(48) «Para terminar. Sobre Sancho Ramírez y su muerte» en Argensola, 5 (Huesca, 1954), p. 353-356.

(49) "Documentos para el estudio de la Numismática navarro-aragonesa medieval» en Caesaraugusta, 6 (Zaragoza, 1955), p. 183-189.

(50) "Las monedas de "Nauara"", en Numario Hispánico, 5 (Madrid, 1957), p. 89-94.

(51) "De nuevo sobre el nacimiento de Alfonso II de Aragón» en Estudios de Edad Media de la Corona de Aragón, 6 (Zaragoza, 1956), p. 203-209.

(52) "Con qué tipo de letra se escribió en Navarra hace mil años», en Revista de Archivos, Bibliotecas y Museos, 63 (Madrid, 1957), p. 409-422.

(53) El mal llamado pacto de Haxama, Santiago de Compostela, 1956 (inédito).

(54) Documentos reales navarro-aragoneses hasta el año 1004, Zaragoza, 1986.

(55) "Nota sobre el obispo Esteban (1099-1130) en Argensola, 8 (Huesca, 1957), p. 59-64.

(56) "Sugerencias sobre la "Chronica Adefonsi Imperatoris" en Cuadernos de Historia de España, 25-26 (Buenos Aires, 1957), p. 317-326. 
(57) «El abaciológico de San Cugat del Vallés en el siglo Xl» en Hispania Sacra, 10 (Madrid, 1957), p. 121-127.

(58) «Diferenciación de las monedas atribuidas a Alfonso el Batallador y a Alfonso II de Aragón» en Caesaraugusta, 11-12 (Zaragoza, 1958), p. 87-94.

(59) «¿Un puente romano?» en Caesaraugusta, 6 (Zaragoza, 1955), p. 243-250.

(60) "Una lectura de la "Chronica Adefonsi Imperatoris"» en Archivos leoneses, 11 (León, 1957), p. 141-143.

(61) Notas documentales sobre Alcañiz, Santiago de Compostela, 1958 (inédita).

(62) «La catedral románica de Jaca. Problemas de cronología» en Pirineos, 27-28 (Zaragoza, 1961-62). Apareció nuevamente ampliado en «El románico de la catedral jaquesa y su cronologia» en Príncipe de Viana, 25 (Pamplona, 1964), p. 187-200.

(63) «La aparición del falso Alfonso I el Batallador» en Argensola, 9 (Huesca, 1958), p. 28-38.

(64) «Dos observaciones al abaciologio del monasterio de San Cosme y San Damián de Burbia" en Archivos leoneses, 13 (León, 1958), p. 163-165.

(65) «¿Dónde estuvo el panteón de los primeros reyes pamploneses? en Príncipe de Viana, 19 (Pamplona, 1958), p. 267-277.

(66) «¿Una moneda conmemorativa aragonesa del siglo XI?» en Caesaraugusta, 15-16 (Zaragoza, 1960), p. 267-187.

(67) «Abades de San Salvador de Leire durante el siglo X» en Saitabi, 15 (Valencia, 1964), p. 31-36.

(68) ¿Cómo se formó España?, Valencia, 1958.

(69) Colección diplomática de Riaza, Segovia, 1959.

(70) «Sobre demografía aragonesa del siglo XIl», en Estudios de Edad Media de la Corona de Aragón, 7 (Zaragoza, 1962), p. 578-598.

(71) «Procesos de la Inquisición de Aragón» en Revista de Archivos Bibliotecas y Museos, 67 (Madrid, 1959), p. 549-599.

(72) «La dinastía Jimena» en Saitabi, 10 (Valencia, 1960), p. 65-79.

(73) Estudios en torno a la división del reino por Sancho el Mayor de Navarra, Pamplona, 1960.

(74) «Relaciones de Aragón y Portugal en el siglo Xl|», en Actas Congreso Histórico de Portugal Medievo, 1 (Braga, 1963), p. 29-40.

(75) "La derrota de Carlomagno y la "Chanson de Roland" " en Hispania, 23 (Madrid, 1963), p. 3-28.

(76) Cartulario de Albelda, $1 .^{a}$ ed., Valencia, 1960, 2. ${ }^{\text {a }}$ ed. Zaragoza, 1981.

(77) Colección diplomática de Cuéllar, Segovia, 1962

(78) Cartulario de Siresa, $1 .^{a}$ ed., Valencia, 1960, 2. ${ }^{a}$ ed., Zaragoza, 1986.

(79) Crónica de Alfonso III, 1. a ed., Valencia, 1960, 2. ${ }^{a}$ ed., Zaragoza, 1971.

(80) "¿Versos del siglo XV?», en Argensola, 11 (Huesca, 1960), p. 233-234.

(81) «La redacción "rotense" de la Crónica de Altonso IIl» en Hispania, 22 (Madrid, 1962), p. 3-22.

(82) "La redacción "ovetense" de la Crónica de Alfonso ll» en Symposium sobre cultura asturiana de la Alta Edad Media (Oviedo, 1967), p. 365-369.

(83) «La "Historia Roderici" y su fecha de redacción" en Saitabi, 11 (Valencia, 1961), p. 241-246.

(84) Crónica de San Juan de la Peña. Texto latino, Valencia, 1961.

(85) «Dos inscripciones asturianas del siglo X» en Saitabi, 14 (Valencia, 1964), p. 27-29.

(86) «Los reyes de Pamplona entre 905 y 970», en Príncipe de Viana, 90-91 (Pamplona, 1963), p. $77-82$.

(87) «Los primeros años de la diócesis de Sigüenza» en Homenaje a Joannes Vincke, 1 (Madrid, 1962-1963), p. 135-148.

(88) Introducción a la Historia de España, Barcelona, 1963, en colaboración. Diecisiete ediciones, la última de 1987.

(89) Cartulario de San Juan de la Peña, I, Valencia, 1962.

(90) Cartulario de San Juan de la Peña, II. Valencia, 1963.

(91) Cartulario de Santa Cruz de la Serós, Valencia, 1966. 
(92) «Notas sobre el valle de Benasque: su economía ganade:a medieval» en Saitabi, 13 (Valencia, 1963), p. 33-42.

(93) Crónicas navarras, Valencia, 1964.

(94) «Un frustrado matrimonio de Alfonso II de Aragón» en Actas del VII Congreso de Historia de la Corona de Aragón, 2 (Barcelona, 1962), p. 263-267.

(95) "Los "Votos de San Millán"”, en Homenaje a Jaime Vicéns Vives (Barcelona, 1965), p. 309-324.

(96) Documentos de Sancho el Mayor, rey de Pamplona, Valencia, 1962 (inédita).

(97) "Una leyenda del "Camino": la muerte de Ramiro I de Aragón» en Príncipe de Viana, 24 (Pamplona, 1963), p. 5-27.

'98) «La conquista de Valencia en la mente de Jaime l» en Saitabi, 12 (Valencia, 1962), p. 117-159.

(99) «El monasterio de San Esteban de Oraste y su emplazamiento» en Argensola, 13 (Huesca, 1962), p. 117-122.

(100) «El arte románico en Aragón durante el siglo Xll», publicado en L'art roman en Aragon au X/० siècle, en "L'information d'Histoire de l'Art», 9 (París, 1964), p. 158-160.

(101) "Poesía navarro-aragonesa primitiva» en Estudios de Edad Media de la Corona de Aragón 8 (Zaragoza, 1967), p. 9-44.

(102) "Monedas que circulaban en Navarra en el siglo XIV y sus valores", en Numisma, 17 (Madrid, 1967), p. 59-66.

(103) «El verso 746 de la "Chanson de Roland"» en Boletín de la Real Academia de Buenas Letras de Barcelona, 31 (Barcelona, 1965-1966), p. 331-332.

(104) Crónica najerense, Valencia, 1965.

(105) «Puntualizaciones sobre la reconquista valenciana», en Ligarzas, 1 (Valencia, 1968), p. 161-178.

(106) «Notas sobre la historiografía leonesa del siglo X» en Archivos leoneses, $39-40$ (León, 1966), p. $157-162$.

(107) «Los primeros años del Hospital de Santa Cristina del Somport», en Príncipe de Viana, 27 (Pamplona, 1966), p. 267-276.

(108) Anales de la Corona de Aragón de Gerónimo Zurita, I, Valencia, 1967.

(109) Anales de la Corona de Aragón de Gerónimo Zurita, II, Valencia, 1967.

(110) Indices de la "Crónica del príncipe de Viana», Valencia, 1971.

(111) «¿Un nuevo rey pamplonés para el siglo IX?», en Príncipe de Viana, 28 (Pamplona, 1967), p. 289-291.

(112) «El texto aragonés de la "Crónica de San Juan de la Peña" en Actas del VIII Congreso de Historia de la Corona de Aragón, 2 (Valencia, 1969), p. 307-310.

(113) Ayerbe. Páginas sobre su historia, Valencia, 1969.

(114) "La elaboración de las "Genealogías de Roda"» en Miscelánea ofrecida al limo. Sr. D. José María Lacarra y de Miguel, Zaragoza, 1968, p. 457-464.

(115) «Barcelona y la narración de Ermold le Noire» en Congresso Luso-Espanhol de Estudios Medievais (Porto, 1968).

(116) Ciclos económicos de la Edad Media Española, Valencia, 1969.

(117) Anales de la Corona de Aragón de Gerónimo Zurita, III, primera parte, Valencia, 1968.

(118) «Anotaciones a Avieno y a su "Ora Marítima" ", en Miscelánea Pericot (Valencia, 1969), p. 187-191.

(119) "La "Tercera Crónica General" y Zurita» en Suma de Estudios en homenaje al llustrísimo Doctor Ángel Canellas López (Zaragoza, 1969), p. 975-977.

(120) "Casualidades y "Ciclos" ( (I). Los «Cuadernos de alcabales» en Departamento de Historia Medieval n. ${ }^{\circ} 1$ (Valencia, 1971), p. 13.

(121) "Valoración de la épica en el contexto histórico español» en Príncipe de Viana, 30 (Pamplona, 1969), p. 233-244.

(122) "Un dato para la cronología de la "Crónica" de Desclot", en Homenaje al profesor Carriazo, 3 (Sevilla, 1973), p. 423-428. 
(123) «La división de Navarra en 1076", en Homenaje a D. José Esteban Uranga (Pamplona, 1971), p. $17-28$.

(124) Atlas histórico. Cómo se formó España, Valencia, 1970.

(125) «Valoración de la Reconquista peninsular» en Principe de Viana, 120-121 (Pamplona, 1970), p. 213-220.

(126) «Cronología del desarrollo de la Peste Negra en la Península Ibérica, en Cuadernos de Historia, 5 (Madrid, 1975), p. 47-66.

(128) «Sobre la nunca reñida batalla de Morella (1084)» en Boletín de la Sociedad Castellonense de Cultura, 49 (Castellón, 1973), p. 97-115.

(129) "Más cronología de la reconquista valenciana» para las Actas del primer congreso de Historia del País Valenciano (inédita).

(130) «Temas eclesiásticos oscenses» en Ligarzas, 3 (Valencia, 1971), p. 17-40.

(131) El "Cantar del Mio Cid» y algunos problemas históricos, Valencia, 1973.

(132) «Valencia. Visión histórica» en Tierras de España (Fundación March) (Madrid, 1985), p. 61-102.

(133) "Casualidades y "Ciclos"" (II). Los Concilios de Castilla" en Departamento de Historia Medieval n. ${ }^{\circ} 2$ (Valencia, 1971), p. 14.

(134) Caffaro. De captione Almerie et Tortuse, Valencia, 1972.

(135) "Casualidades y "Ciclos"» (III). Las repoblaciones de los reyes astur-leoneses" en Departamento de Historia Medieval $\mathrm{n}^{\circ} 3$ (Valencia, 1971), p. 16.

(136) "Una variación en el "Camino de Santiago"» en Estudios de Edad Media de la Corona de Aragón, 9 (Zaragoza, 1973), p. 49-70.

(137) "Casualidades y "Ciclos"" (IV). Recuento de monedas musulmanas españolas", en Departamento de Historia Medieval, n. ${ }^{\circ} 6$ (Valencia, 1971), p. 16.

(138) Anales de la Corona de Aragón de Gerónimo Zurita, III, segunda parte, Valencia, 1972.

(139) Trabajos de investigación I, Valencia, 1972.

(140) «¿Un ataque aragonés a Zaragoza, en 1089?» en Estudios de Edad Media de la Corona de Aragón 10 (Zaragoza, 1975), p. 679-688.

(141) Prólogo e índices de Idrizi, Geografía de España, Valencia, 1974, p. 5-14; 217-260.

(142) "San Juan, hagiotopónimo del Alto Aragonés», en Archivos leoneses, 55-56 (León, 1974), p. $189 \cdot 196$.

(143) La fecha de redacción de la «Crónica Pseudo Isidoriana», Valencia, 1974 (inédita).

(144) "Los primeros años del monasterio de San Millán» en Príncipe de Viana, 132-133 (Pamplona, 1973), p. 181-200.

(145) Cartulario de San Juan de la Peña, III, Valencia, 1974 (inédito).

(146) "La corona de Aragón» (Caja de Ahorros y Monte de Piedad de Zaragoza, Aragón y Rioja) (Zaragoza, 1976), p. 23-30.

(147) «Sobre los límites de la dominación carolingia en el Pirineo navarro-aragonés» en Actas del VII Congreso Internacional de Estudios Pirenaicos, sección V (Jaca, 1983), p. 287-290.

(148) «Dos notas sobre Sancho el Mayor» en Homenaje al Dr. D. Juan Reglá Campistol, 1 (Va. lencia, 1975), p. 73-77.

(149) “¿e terminó de escribir la "Silense"?» en Homenaje a fray Justo Pérez de Urbel, 1 (Silos, 1976), p. 305-308.

(150) La creación del reino de Valencia, Lección inaugural del curso 1974-75 (Valencia, 1974).

(151) Jaca. Documentos municipales (981-1263), Valencia, 1975.

(152) Cartulario de San Millán de la Cogolla (759-1076), Valencia, 1976.

(153) Los orígenes del reino de Valencia, I, 1. ${ }^{a}$ ed., Valencia, 1976, 4. ${ }^{a}$ ed., Zaragoza, 1980.

(154) «Historiografía castellana medieval» en Príncipe de Viana (en prensa).

(155) La descripción más antigua de la catedral de Jaca (inédita).

(156) "Las "sesmas" de la Comunidad de Teruel», en Teruel, 57-58 (Teruel, 1977), 11 páginas.

(157) «La tierra de Aragón a príncipios del siglo XVIl» en Estudis, 4 (Valencia, 1975), p. 12-24.

(158) «La reconquista de Valencia y Murcia», en Jaime l y su época. X Congreso de Historia de la Corona de Aragón (Zaragoza, 1979), p. 149-165. 
(159) «La creación de la frontera entre Aragón - Valencia y el espíritu de frontera-» en Homenaje al Profesor don José María Lacarra de Miguel», 2 (Zaragoza, 1977), p. 179-203.

(160) «La merindad de Sangüesa y su creación» en Príncipe de Viana (en prensa).

(161) «El sentimiento antileonés en el "Cantar del Mío Cid"' en La España Medieval. Homenaje al profesor Julio González, 1 (Madrid, 1901), p. 551-574.

(162) Dos actitudes ante la reconquista de Valencia, Valencia 1976, reproducido en el 179.

(163) La creación de la Corona de Aragón, Valencia, 1977.

(164) Entidades políticas en la reconquista de Valencia, Valencia, 1977.

(165) Desclot: un historiador valenciano recuperado, Valencia, 1977.

(166) La leyenda del origen ilerdense de trescientas valencianas, Valencia, 1978.

(167) Los almorávides, el idioma romance y los valencianos, Zaragoza, 1978, reproducido en el 179 .

(168) Documentos de Ramiro / de Aragón, Zaragoza, 1977 (inédito).

(169) Documentos de Santa Cristina de Somport, Zaragoza (en prensa).

(170) Historia de Aragón. La formación territorial, Zaragoza, 1981.

(171) «¿Una canción de gesta perdida? La muerte de Pedro de Ahones», en Etudes de Philologie Romane et d'Histoire Litteraire offerts à Jules Horrent à l'occasion de son soixantième anniversaire (Liege, 1980), p. 489-501.

(172) La "Chanson de Roland» y algunos problemas históricos, Zaragoza, 1985.

(173) "La conquista de los reinos de Mallorca y de Valencia» en Historia de España dirigida por Menéndez Pidal (en prensa).

(174) «Los estudios sobre Edad Media aragonesa» en I Jornadas sobre el estado actual de los estudios sobre Aragón. Teruel. (Zaragoza, 1979), p. 235-252.

(175) La formación de Aragón, Zaragoza, 1979.

(176) "La construcción de la iglesia del castillo de Atarés (961)" en Miscelánea de estudios en honor de don Antonio Durán Gudiol (Sabiñánigo, 1981), p. 269-276.

(177) La campana de Huesca, Zaragoza, 1979.

(178) Los amantes de Teruel, Zaragoza, 1979.

(179) Los origenes del reino de Valencia, 2. Zaragoza, 1979.

(180) El compromiso de Caspe, Zaragoza, 1980.

(181) «La lengua de los textos jurídicos y documentos de aplicación del derecho en el siglo XIII en Aragón", en II Jornadas sobre el estado actual de los estudios sobre Aragón. Huesca (Zaragoza, 1980), p. 441-444.

(182) «Índices demográficos familiares hasta el siglo XIV en Aragón» en /I Jornadas sobre el estado actual de los estudios sobre Aragón. Huesca (Zaragoza, 1980), p. 585-589.

(183) «Orrios medievales en Aragón», en III Jornadas sobre el estado actual de los estudios sobre Aragón (Zaragoza, 1981), p. 913-915.

(184) "Los caminos que unían Aragón con Francia durante la Edad Media" en Les communications dans la Peninsule Ibérique au Moyen Age (París, 1981), p. 21-27.

(185) "Otro dato sobre la cronología del "Cantar de Mio Cid" en Estudios en memoria del Profesor D. Salvador de Moxó, 2 (Madrid, 1982), p. 673-680.

(186) "Les "Varraques de los jaqueses" y "Les Barraques dels reals" ", en Estudios en Homenaje al Dr. Antonio Beltrán Martínez (Zaragoza, 1985), p. 1015-1018.

(187) Historia de Aragón. Literatura medieval l, Zaragoza, 1981.

(188) “Una nueva lectura del plano de Caesaraugusta romana» en Homenaje al Prof. García y Bellido (Madrid, 1988).

(189) Las diócesis aragonesas, Zaragoza, 1984.

(190) Historia de Aragón. Divisiones administrativas, Zaragoza, 1983.

(191) Colaboración en Historia de la Universidad de Zaragoza, Zaragoza, 1983.

(192) «La reina Leodegundia» en Homenaje al Prof. Udina Martorell (en prensa).

(193) "El Valle de Echo y la "Chanson de Roland"» en II Semana Cultural del Valle de Hecho (Zaragoza, 1982), p. 59-62.

(194) «Los archivos para la historia de la Ciencia» en Actas del I/ Congreso de la Sociedad Española de Historia de la Ciencia, I (Zaragoza, 1984), p. 228-233. 
(195) «Pobres y marginados en el primitivo Aragón» en Aragón en la Edad Media. Estudios de Economía y Sociedad, 5 (Zaragoza, 1983), p. 7-22.

(196) El patrimonio Real en Aragón durante la Edad Media, en colaboración con Atanasio Sinués Ruiz, Zaragoza, 1986.

(197) «Historia d'historiografia valenciana recent» en Raons d'ldentitat (Valencia, 1985), $p$ 187-204.

(198) Historia de Aragón. Los pueblos y los despoblados, I, Zaragoza, 1984.

(199) Historia de Aragón. Los pueblos y los despoblados, II, Zaragoza, 1985.

(200) Historia de Aragón. Los pueblos y los despoblados, III, Zaragoza, 1986.

(201) «Inmigración medieval de lusitanos al Alto Aragón» en Argensola, 22 (Huesca, 1980), p. 249-259.

(202) Estudio histórico-geográfico del valle de Bielsa (Huesca), en colaboración con otros autores, Huesca, 1986.

(204) «Las Ciencias Sociales sobre Aragón. Aspectos didácticos», en Reunión sobre didáctica sobre Aragón. Teruel, julio 1985 (en prensa).

(205) "Sobre la conquista de la Rioja por los pamploneses" en Homenaje a José María Lacarra, 2 (Murcia, 1987), p. 755-763.

(206) «El topónimo "Torre/Torres" en Aragón», en Homenaje al profesor Juan Torres Fontes, 2 (Murcia, 1987), p. 27-37.

(207) «Las pardinas», en Aragón en la Edad Media. Estudios de economía y sociedad, 7 (Zaragoza, 1987), p. 27--37.

(208) «La documentación relativa a construcciones de iglesias en Aragón durante los siglos IX y X» en Homenaje a don Federico Balaguer Sánchez (Huesca, 1987), p. 37-42.

(209) Los esponsales de la reina Petronila y la creación de la Corona de Aragón, Zaragoza, 1987.

(210) Historia de Aragón. Creación y desarrollo de la Corona de Aragón, Zaragoza, 1987.

(211) "Las "Cantigas" de Alfonso el Sabio relativas a Santa Maria de Salas", en Homenaje al Prof. Alvaro Santamaría (Palma de Mallorca).

NOTAS

(1) La relación bibliográfica ha sido tomada del volumen VII de Aragón en la Edad Media, p. $11-22$ 